\title{
Greenhouse gas analysis of air samples collected onboard the CARIBIC passenger aircraft
}

\author{
T. J. Schuck ${ }^{1}$, C. A. M. Brenninkmeijer ${ }^{1}$, F. Slemr ${ }^{1}$, I. Xueref-Remy ${ }^{2}$, and A. Zahn ${ }^{3}$ \\ ${ }^{1}$ Max-Planck-Institut für Chemie (MPI), Air Chemistry Division, Mainz, Germany \\ ${ }^{2}$ Laboratoire des Sciences du Climat et de l'Environnement (CNRS), CEA Saclay Orme des Merisiers, Gif sur Yvette, France \\ ${ }^{3}$ Institute for Meteorology and Climate Research (IMK), Forschungszentrum Karlsruhe, Karlsruhe, Germany
}

Received: 6 March 2009 - Published in Atmos. Meas. Tech. Discuss.: 23 March 2009

Revised: 4 August 2009 - Accepted: 6 August 2009 - Published: 21 August 2009

\begin{abstract}
CARIBIC (Civil Aircraft for the Regular Investigation of the atmosphere Based on an Instrument Container) is a long-term atmospheric measurement program based on the use of a comprehensive scientific instrument package aboard a commercial passenger aircraft. In addition to realtime measurements, whole air sampling is performed regularly at cruising altitudes in the tropical middle troposphere and the extra-tropical UT/LS region. Air samples are analyzed for greenhouse gases, NMHCs, halocarbons, and trace gas isotopic composition. The routinely performed greenhouse gas analysis comprises gas chromatography measurements of $\mathrm{CO}_{2}, \mathrm{CH}_{4}, \mathrm{~N}_{2} \mathrm{O}$ and $\mathrm{SF}_{6}$.

The air sampling procedure, the GC system and its performance are described. Comparisons with similar systems employed in other laboratories and a comparison with results from a $\mathrm{CO}_{2}$ in-situ analyzer that is also part of the CARIBIC instrumentation are shown. In addition, the time series of $\mathrm{CO}_{2}$, obtained from the collection of 684 samples at latitudes between $30^{\circ} \mathrm{N}$ and $56^{\circ} \mathrm{N}$ on 21 round trips out of Germany to different destinations in Asia between November 2005 and October 2008, is presented. A time shift in the seasonal cycle of about one month was observed between the upper troposphere and the tropopause region. For two sets of return flights from Germany to the Philippines the relationship between the four greenhouse gases is briefly discussed.
\end{abstract}

\section{Introduction}

CARIBIC (Civil Aircraft for the Regular Investigation of the atmosphere Based on an Instrumented Container, www.caribic-atmospheric.com) is one of three current at-

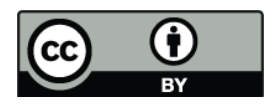

Correspondence to: T. J. Schuck (schuck@mpch-mainz.mpg.de) mospheric chemistry and composition programs based on commercial passenger aircraft (Brenninkmeijer et al., 2005; IGAC, 2007). Such programs provide the possibility of regularly monitoring atmospheric trace constituents on a longterm basis, i.e. over several years. These aircraft projects are unique in that large sections of the globe are covered, that background tropospheric air is probed, and that, depending on the flight routes, a large fraction of the flight time is spent in the tropopause region and the lowermost stratosphere.

Isentropic transport of tracers across the extra-tropical tropopause has been identified as an important mechanism that couples the chemical composition of the upper troposphere and the lowermost stratosphere (Holton et al., 1995). It was shown that above the tropopause a mixing layer exists in which trace gas mixing ratios strongly change with distance from the tropopause, and where stratospheric and tropospheric tracers are closely anti-correlated (Fischer et al., 2000; Zahn et al., 2000). Various studies have been carried out investigating, for example, the seasonality of transport processes or identification of different source regions (e.g. Engel et al., 2006, and references therein). While systematic measurements of the atmospheric composition could help to gain a better understanding of the mixing processes that take place in the tropopause region, in-situ measurements are still mostly restricted to individual campaigns employing research aircraft, and with few exceptions no regular observations are performed. Carrying scientific equipment for measurement of trace gases and aerosols onboard commercial aircraft, as it is done within the CARIBIC project, makes it possible to access this part of the atmosphere regularly during all seasons.

The aim of the CARIBIC experiment is the regular measurement of a large set of atmospheric tracers using various techniques (Brenninkmeijer et al., 2007). In addition to real time measurements of aerosols and trace gases, the CARIBIC instrument package includes sampling of air and

Published by Copernicus Publications on behalf of the European Geosciences Union. 
aerosols. For the subsequent analysis these samples are removed from the container after completion of a series of flights. The air samples allow for the precise measurements of long lived trace gases that are difficult to measure in-flight. The samples are analyzed for the main greenhouse gases carbon dioxide $\left(\mathrm{CO}_{2}\right)$, methane $\left(\mathrm{CH}_{4}\right)$, nitrous oxide $\left(\mathrm{N}_{2} \mathrm{O}\right)$, and sulfur hexafluoride $\left(\mathrm{SF}_{6}\right)$ as well as for various non-methane hydrocarbons (NMHCs), halocarbons, and isotope ratios of $\mathrm{CO}_{2}, \mathrm{CH}_{4}$, and $\mathrm{H}_{2}$.

These measurements are relevant for the interpretation of the complete data set, because they contain information about the influence of the biosphere $\left(\mathrm{CO}_{2}, \mathrm{CH}_{4}, \mathrm{~N}_{2} \mathrm{O}\right)$ (Wuebbles and Hayhoe, 2002; Mosier et al., 1998) and about stratospheric processes $\left(\mathrm{CH}_{4}, \mathrm{~N}_{2} \mathrm{O}\right.$ ) (Wuebbles and Hayhoe, 2002; Boering et al., 1996; Nevison et al., 2004). SF 6 also fulfills the role of a tracer of surface emissions from populated industrialized regions (Maiss and Brenninkmeijer, 1998). In addition, $\mathrm{SF}_{6}$ and $\mathrm{CO}_{2}$ are tracers that allow estimates of the timing and the extent of large scale transport processes (Bönisch et al., 2008).

\section{Air sampling procedure}

The new CARIBIC system is based on a fully automated instrument package (Brenninkmeijer et al., 2007). Since December 2004, it is employed monthly aboard a Lufthansa Airbus A340-600 passenger aircraft equipped with an advanced multi-probe inlet system. For the collection of whole air samples the CARIBIC measurement container houses the air sampling device TRAC (Triggered Retrospective Air Collector) (Brenninkmeijer et al., 2007). This air sampling system consists of a computer unit that controls the sampling of air, a three-stage pumping unit, and two separate sample units, each containing 14 glass cylinders with a volume of 2.671 each. Six of these identically constructed sample units exist (length: $600 \mathrm{~mm}$, width: $622 \mathrm{~mm}$, height: $360 \mathrm{~mm}$, weight: $49 \mathrm{~kg}$ ). One set of two units is integrated in the container during the monthly flights while the other pairs are circulating among the partner laboratories for analyses. Inside each sample unit, two 16-position valves (Valco) are used to switch between the cylinders with one valve for the inlet side of the cylinders and one for the outlet. Stainless steel tubing is used for connecting the glass cylinders to the valves. The two surplus positions of the valves are shortcircuited, also using stainless steel tubing. The common inlet line is equipped with a $2 \mu \mathrm{m}$ sintered stainless steel filter (Swagelok) to remove particles from the sampled air. The pumping unit houses two metal bellow pumps (Senior Aerospace Metal Bellows, 28823-7), the first with its two bellows in parallel, the second pump with its two bellows in series, resulting in a three-stage pumping unit. The inlet pressure during a flight is about 200-300 mbar and flow rates of 20-301/min (STP) are obtainable. In between the sampling periods the pumps are switched off in order to save power and reduce heat production.

Prior to pressurization, the sample cylinders are flushed with outside air for $5 \mathrm{~min}$. In laboratory experiments, the mean time for the total air volume inside the canister to be exchanged has been determined as a function of ambient pressure. It is approximately $0.5 \mathrm{~min}$, so that during the flushing time the air inside the sample cylinder is exchanged about 10 times. After 5 min of flushing, the outlet valve is switched to the next position. The total sampling time is the sum of the time interval between the switching points of the outlet and the inlet valve and the time needed to replace the air volume inside the canister during the flushing period at the respective ambient pressure. Depending on the flight altitude, the resulting total sample collection times range from $0.5 \mathrm{~min}$ to $1.5 \mathrm{~min}$, corresponding to a spatial resolution of about 7 to $21 \mathrm{~km}$.

A pressure sensor between the outlet of the pumping system and the inlet valve of the sample unit controls the pressure inside the sample cylinder. Once the final pressure of 4.5 bar is reached, the inlet valve is also switched. To prevent overpressure, a mechanical pressure release valve is set to open at 5 bar. As the pressure measured in-flight is the sum of ambient pressure and ram pressure and depends on the container temperature, the actual pressure in the laboratory at the time of analysis varies and is lower than 4.5 bar. It ranges from 3.5 to 4.2 bar corresponding to a sample volume of about 9 to 111 (STP).

To avoid sampling of polluted air in the vicinity of airports, an upper pressure cut-off of $480 \mathrm{mbar}$ is applied. The sampling procedure starts when the outside pressure falls below this threshold, and it stops as soon as the ambient pressure exceeds this value. The sampling points are evenly distributed over the expected flight time and, depending on the flight route, samples are taken every 30 to $60 \mathrm{~min}$. The projected use as an air sampling system triggered by observed events has not yet been put into practice. In contrast to event triggered sampling, such as a sudden rise in carbon monoxide, regular sampling leads to a distribution of samples that is more representative of the various air masses crossed by the aircraft.

One set of monthly flights consists of either two or four flight legs. During the first leg all 28 canisters are pressurized. On the following flight leg(s) half of them are vented, and the flushing with ambient air for $5 \mathrm{~min}$ is repeated to remove all air from the previous flight prior to sampling. This procedure ensures that the maximum number of cylinders is filled, even in case of changes to the flight schedule or technical failure of the equipment. In 2008, sampling was $100 \%$ successful with only one sample out of 308 being missed when the flight destination was reached prior to the scheduled arrival time. In 2006 and 2007 an average duty cycle of $96 \%$ was achieved.

After returning from the last flight leg, the container is removed from the aircraft. Next, the sample units are 
removed, and the samples circulate between up to five European labs for measurements of greenhouse gases, nonmethane hydrocarbons (Baker et al., 2009), halocarbons (Fraser et al., 1999; O'Sullivan, 2007) and isotopic composition $\left({ }^{18} \mathrm{O}\left(\mathrm{CO}_{2}\right),{ }^{13} \mathrm{C}\left(\mathrm{CO}_{2}\right)\right.$ (Assonov et al., 2009), $\mathrm{D}\left(\mathrm{H}_{2}\right)$, ${ }^{13}\left(\mathrm{CH}_{4}\right)$ (Rhee et al., 2004)).

\section{Characterization of the greenhouse gas GC system}

The greenhouse gas analysis comprises measurements of $\mathrm{CH}_{4}, \mathrm{CO}_{2}, \mathrm{~N}_{2} \mathrm{O}$, and $\mathrm{SF}_{6}$ using a HP 6890 gas chromatograph equipped with a flame ionization detector (FID) for measuring $\mathrm{CH}_{4}$ and $\mathrm{CO}_{2}$ and an electron capture detector (ECD) for $\mathrm{N}_{2} \mathrm{O}$ and $\mathrm{SF}_{6}$. This system was initially designed and installed by D. Worthy (Env. Canada), however, details have been modified since. Figure 1 shows a schematic of the setup with the valve positions at the beginning of a measurement cycle. The system has been designed to enable the automated measurement of a sequence of 28 samples. For the analysis of CARIBIC samples the two sample units and a working standard are connected to the system via an 8position selector valve that controls the sampling source.

One single measurement cycle runs for $12 \mathrm{~min}$. Loading of the sample and its passage through the system are controlled by four valves. The two valves controlling the flow through the two sample loops are operated synchronously. They are therefore both labeled valve 1 and are treated as one valve in this description. Valve 2 controls the flow from the sample loop towards the ECD, valve 5 towards the FID channel. When a cycle begins, the Porapak column of the ECD-channel is still being flushed backwards with the carrier gas $\mathrm{Ar} / \mathrm{CH}_{4}$, back flushing stops after $0.2 \mathrm{~min}$. This is the time step shown in Fig. 1.

Loading of a sample starts after $0.5 \mathrm{~min}$. The two sample loops are connected in series with the smaller $10 \mathrm{ml}$ loop for the FID channel upstream. The ECD sample loop has a volume of $15 \mathrm{ml}$. A pressure of $275 \mathrm{mbar}$ (relative to ambient pressure) is applied for $0.5 \mathrm{~min}$ for loading the sample loops, afterwards another $0.5 \mathrm{~min}$ are allowed for equilibration with ambient pressure. $1.5 \mathrm{~min}$ after the start of a cycle valve 1 is switched and the respective carrier gas starts flowing through each sample loop. Back flushing, which is controlled by the switching of valve 2 , starts after $8.3 \mathrm{~min}$ and lasts for $3.7 \mathrm{~min}$.

Both channels are equipped with packed polymer columns that are kept in a single oven. The FID channel is equipped with a Porapak Q 3/4" column (10 ft, 100/120 mesh). $\mathrm{N}_{2}$ (quality 5.0) is used as carrier gas at a constant flow rate of $50 \mathrm{ml} / \mathrm{min}$. The detector is kept at $220^{\circ} \mathrm{C}$ and it is operated with a flow of synthetic air of $250 \mathrm{ml} / \mathrm{min}$ and a flow of $\mathrm{H}_{2}$ of $80 \mathrm{ml} / \mathrm{min}$ that is directed via a methanizer While $\mathrm{CH}_{4}$ is detected directly, $\mathrm{CO}_{2}$ is converted to $\mathrm{CH}_{4}$ using a nickel catalyst. In the beginning of a measurement cycle, the methanizer is bypassed and $\mathrm{CH}_{4}$ from the sample is directly detected by the FID. After 3.9 min valve 5 is switched and the flow then passes through the methanizer. $\mathrm{CO}_{2}$ from the sample is converted to $\mathrm{CH}_{4}$ which can be detected by the FID. After 7.5 min valve 5 is switched back to its initial position. The efficiency of the methanizer is monitored by comparing the ratio of $\mathrm{CH}_{4}$ and $\mathrm{CO}_{2}$ mixing ratios and peak areas for each chromatogram. It has been above $96 \%$ for all samples analyzed.

On the ECD channel, two columns in series are needed for the separation of $\mathrm{N}_{2} \mathrm{O}$ and $\mathrm{SF}_{6}$. A Porapak Q 1/8" $(6 \mathrm{ft}$, 80/100 mesh) column and a HayeSep Q 1/8" (6 ft, 80/100 mesh) column are used. The ECD is operated at a temperature of $390^{\circ} \mathrm{C}$ with $\mathrm{Ar} / \mathrm{CH}_{4}(5 \%$, ECD quality) as carrier gas at a flow rate of $90 \mathrm{ml} / \mathrm{min}$ and an anode flow rate of $3 \mathrm{ml} / \mathrm{min}$. Figure 2 shows typical examples of the chromatograms for a working standard. At an oven temperature of $50^{\circ} \mathrm{C}$ the retention times are $1.93 \mathrm{~min}$ for $\mathrm{CH}_{4}, 3.25 \mathrm{~min}$ for $\mathrm{CO}_{2}, 4.33 \mathrm{~min}$ for $\mathrm{N}_{2} \mathrm{O}$, and $5.52 \mathrm{~min}$ for $\mathrm{SF}_{6}$.

During the analysis of CARIBIC samples four consecutive injections per sample are made, the results of which are averaged. The precision of the data points is calculated from the standard deviation of those four injections. The typical precision obtained on the system is $0.17 \%$ for $\mathrm{CH}_{4}, 0.08 \%$ for $\mathrm{CO}_{2}, 0.15 \%$ for $\mathrm{N}_{2} \mathrm{O}$, and $1.5 \%$ for $\mathrm{SF}_{6}$. In between samples, three injections of a running standard gas are made. This also starts and ends a series of measurements so that each sample analysis is bracketed by a series of measurements of the running standard. The analysis of a complete set of 28 samples takes approximately $48 \mathrm{~h}$ during which slow ambient pressure and temperature changes can occur. This has an influence on the sensitivity of the detectors, especially on that of the ECD. The procedure of alternating measurements of the running standard and samples allows to correct for these drifts.

For the calculation of mixing ratios, peak heights and areas are determined using the numerical integration routine of the Agilent Chemstation software (Rev.A.10.01) that is controlling the GC. The gas mixing ratios are calculated separately from the peak area and from the peak height, and the results of the two independent numerical analyses are compared. If they agree within their errors, the mixing ratio of a sample is taken to be the average of both numbers.

\subsection{Standard gases and calibration}

The calibration of the analysis relied on four NOAA ESRL standards until April 2009. Then the number of standards was extended to seven to keep up with increasing $\mathrm{CO}_{2}$ and $\mathrm{SF}_{6}$ levels. Table 1 shows the mixing ratios of $\mathrm{CH}_{4}$ (adjusted CMDL83 scale (Dlugokencky et al., 2005)), $\mathrm{CO}_{2}$ (WMOX2007 scale), $\mathrm{N}_{2} \mathrm{O}$ (NOAA 2006 scale (Hall et al., 2007)), and of $\mathrm{SF}_{6}$ (NOAA 2006 scale (Hall et al., 2007)). For the cylinder CA 02603 the $\mathrm{CO}_{2}$ mixing ratio on the most recent scale is unknown (D. Kitzis, private communication, 2008).

Table 1 also shows the results of the calibration of all four working standards. KOMP1 was filled on top of the 


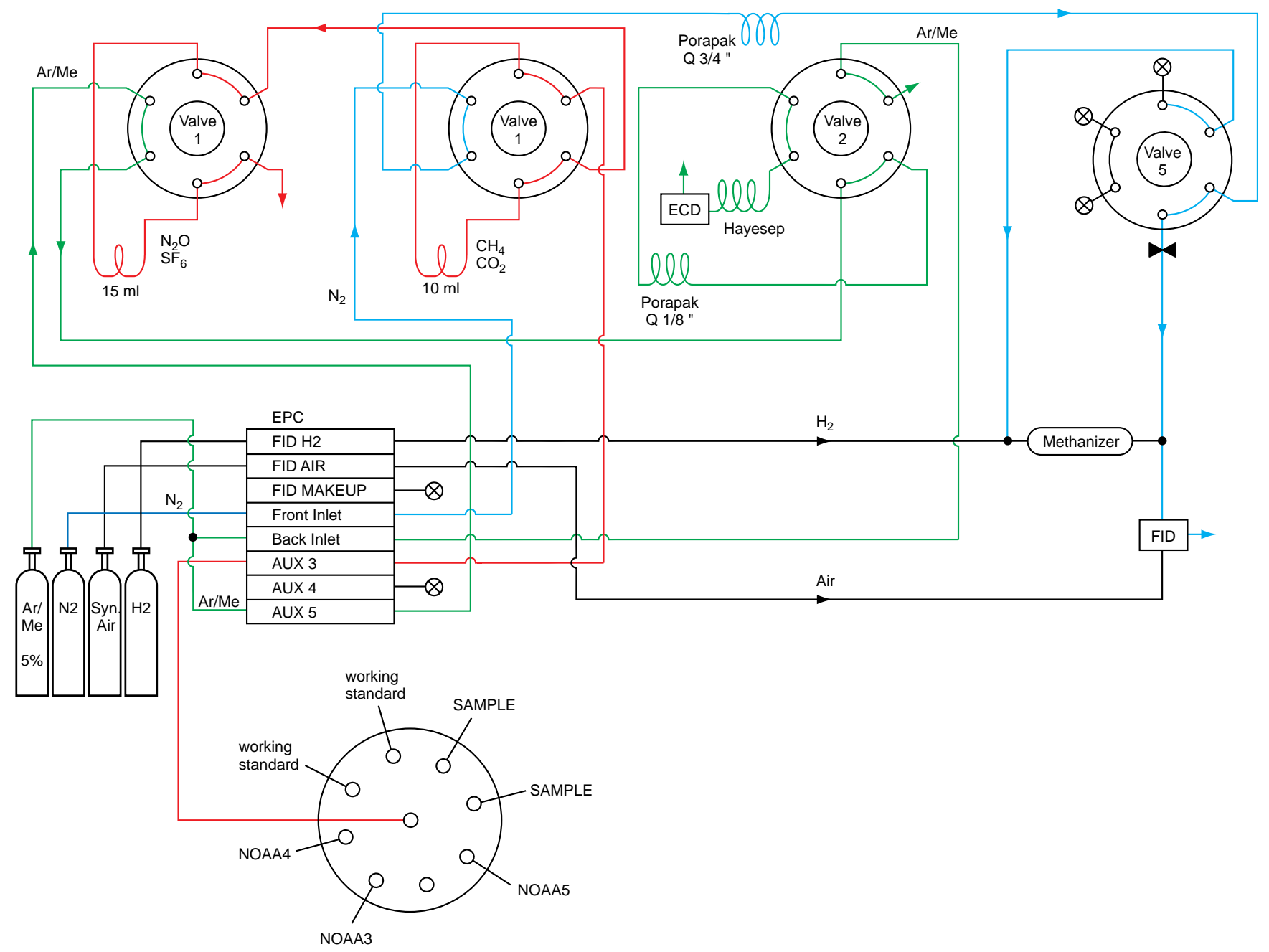

Fig. 1. Schematic layout of the GC-system for the detection of greenhouse gases with all valves in their positions at the beginning of a measurement cycle. The two valves named "valve 1 " have already switched to their position for loading the sampling loops, valve 2 is in the position for directing the carrier gas flow through the columns of the ECD channel, and the flow through valve 5 is directed to the methanizer.

institute's building in Mainz, Germany, in September 2005. It has been used as running standard until December 2007. Presently, SIL194 is used for that purpose. SIL194 and SIL195 have been filled at the Schauinsland observatory in southern Germany (1205 m a.s.l.) (Schmidt et al., 2003) in September 2005, SIL196 in November 2005. All working standards have been prepared using Drierite $\left(\mathrm{CaSO}_{4}\right)$ as drying agent.

The working standard that is used as the running standard for the analysis of the CARIBIC whole air samples is calibrated against the NOAA standards monthly the day before the analysis of samples. The two working standards that are not used in the monthly measurements are also calibrated regularly to check their stability. This is done about once every three months. It has been found that in the range that is covered by the NOAA standards a linear function is the best approximation of the detector response for all measured gases. The slope of the response line as determined in the separate calibration run is taken into account for the actual sample analysis.

In Table 1, the number of calibration runs performed up to now is given in brackets for each standard. Only measurements since April 2009 are included because they are more accurate than the ones before that were based on fewer standards. While the extension of the calibration scale after obtaining new standard from NOAA ESRL resulted in only minor changes of $\mathrm{CH}_{4}, \mathrm{CO}_{2}$, and $\mathrm{N}_{2} \mathrm{O}$ (changes within the range of the precision), a larger correction was found for $\mathrm{SF}_{6}$. For SIL196 the calibration series includes one measurement performed at the Max Planck Institute for Biogeochemistry in Jena (Germany). The numbers given are the arithmetic means of all measurements. No drift within the precision of 
Table 1. Mixing ratios of $\mathrm{CH}_{4}, \mathrm{CO}_{2}, \mathrm{~N}_{2} \mathrm{O}$, and $\mathrm{SF}_{6}$ of NOAA standards and working standards. For the working standards the error is calculated from the standard deviation of the mean of several independent calibration runs (number of runs given in brackets). For SIL196 one measurement performed at the Max Planck Institute for Biogeochemistry in Jena is included.

\begin{tabular}{lcccc}
\hline & $\mathrm{CH}_{4}[\mathrm{ppb}]$ & $\mathrm{CO}_{2}[\mathrm{ppm}]$ & $\mathrm{N}_{2} \mathrm{O}[\mathrm{ppb}]$ & $\mathrm{SF}_{6}[\mathrm{ppt}]$ \\
\hline CA 02603 & 1837.50 & - & 311.90 & 4.04 \\
CA 04450 & 1797.92 & 367.65 & 316.00 & 4.77 \\
CA 06883 & 1684.13 & 373.17 & 304.80 & 3.82 \\
CA 06890 & 1887.30 & 382.95 & 325.60 & 4.78 \\
CA 05541 & 1845.10 & 400.68 & 322.80 & 6.87 \\
CA 05541 & 1952.20 & 432.36 & 342.82 & 8.66 \\
CA 05541 & 1706.50 & 414.32 & 328.82 & 7.97 \\
& & & & \\
KOMP1 & $1865.08 \pm 0.35$ & $378.67 \pm 0.04$ & $320.07 \pm 0.04$ & $6.04 \pm 0.01$ \\
$(n=2)$ & & & & \\
SIL194 & $1866.40 \pm 0.34$ & $384.68 \pm 0.03$ & $323.10 \pm 0.04$ & $6.20 \pm 0.01$ \\
$(n=5)$ & & & & \\
SIL195 & $1890.33 \pm 0.25$ & $381.15 \pm 0.03$ & $324.23 \pm 0.05$ & $6.00 \pm 0.01$ \\
$(n=4)$ & & & & \\
SIL196 & $1843.33 \pm 0.12$ & $374.89 \pm 0.04$ & $320.58 \pm 0.06$ & $5.96 \pm 0.01$ \\
$(n=5)$ & & & & \\
\hline
\end{tabular}

the system as given above has been observed in the mixing ratios.

\subsection{The effect of water vapor}

Air sampling aboard the CARIBIC aircraft takes place at altitudes between $7 \mathrm{~km}$ and $12.5 \mathrm{~km}$ (with $\sim 96 \%$ of the samples being collected at the cruising altitude range of $8.5 \mathrm{~km}$ to $12.5 \mathrm{~km}$ ). Air sampling for the CARIBIC trace gas measurements is perpendicular to the flight direction. The trace gas probe of the inlet system, from which ambient air is sampled into the flasks, is oriented parallel to the flight direction. Its forward facing orifice is $16 \mathrm{~mm}$ in diameter, and its rear outlet orifice is $12 \mathrm{~mm}$ in diameter. From the center of the flow through this forward facing probe a fraction of the air flow is withdrawn $15 \mathrm{~cm}$ behind the opening orifice via a perpendicular pick up tube. A detailed description of the CARIBIC inlet inlet system is given in Brenninkmeijer et al. (2007).

Butenhoff and Khalil (2002) pointed out that if drying is not applied either prior to pressurization of air samples or prior to analysis, the possibility of water vapor condensation inside the sample canister needs to be taken into account. The saturation pressure of water at a laboratory temperature of $21^{\circ} \mathrm{C}$ is $24.87 \mathrm{mbar}$ (Wexler, 1976). Assuming a pressure of 4 bar inside a sample canister and a laboratory temperature of $21^{\circ} \mathrm{C}$, even an exceptionally high water vapor content of a sample of $5000 \mathrm{ppm}$ corresponds to a relative humidity in the sample of $\sim 80 \%$ (vapor pressure of $\sim 20 \mathrm{mbar}$ ) (Wexler, 1976; Buck, 1981), which is still below saturation.

Water vapor is detected by two instruments in the CARIBIC container, namely a two-channel photo-acoustic laser spectrometer and a chilled mirror frost point hygrome- ter. The water probe of the inlet contains two separate orifices, one facing flight direction (total water) and one pointing perpendicular (water vapor only), so that gaseous and condensed water can be distinguished (Brenninkmeijer et al., 2007). The actual water content of a sample can be estimated from integrating the continuously measured total water content (the sum of gaseous water and cloud water) of the ambient air over the sampling time. For about $96 \%$ of the samples the water content is below $500 \mathrm{ppm}$, corresponding to roughly $8 \%$ relative humidity in the laboratory. Only for about $2 \%$ of the samples the water content exceeds $1000 \mathrm{ppm}$. As the relative humidity thus is well below $100 \%$ for all samples only the volumetric correction

$x_{\text {dry }}=x_{\text {measured }} \cdot\left(1+x_{\mathrm{H}_{2} \mathrm{O}}\right)$

needs to be taken into account to obtain dry mixing ratios $x_{\text {dry }}$ from the measured ones $x_{\text {measured }}$ with $x_{\mathrm{H}_{2} \mathrm{O}}$ being the mole fraction of water in the sample. This correction factor is applied to all results of the analysis. With $\sim 96 \%$ samples containing less than $500 \mathrm{ppm}$ of water, the correction factor $1+x_{\mathrm{H}_{2} \mathrm{O}}$ is usually below the average relative error of the measured mixing ratios.

To experimentally verify the absence of a significant water vapor effect, test measurements with a drying tube were performed for 14 samples collected during a flight from Frankfurt to Chennai (India) that took place in April 2008. The GC-analysis was repeated for a set of 14 samples with a drying tube containing $\mathrm{Mg}\left(\mathrm{ClO}_{4}\right)_{2}$. From the integration of the continuously measured total water content of the ambient air the water content of these samples was calculated to be $70.1 \mathrm{ppm}$ on average, ranging from $7.2 \mathrm{ppm}$ to $225.3 \mathrm{ppm}$. The measurements with and without the drying tube agreed 

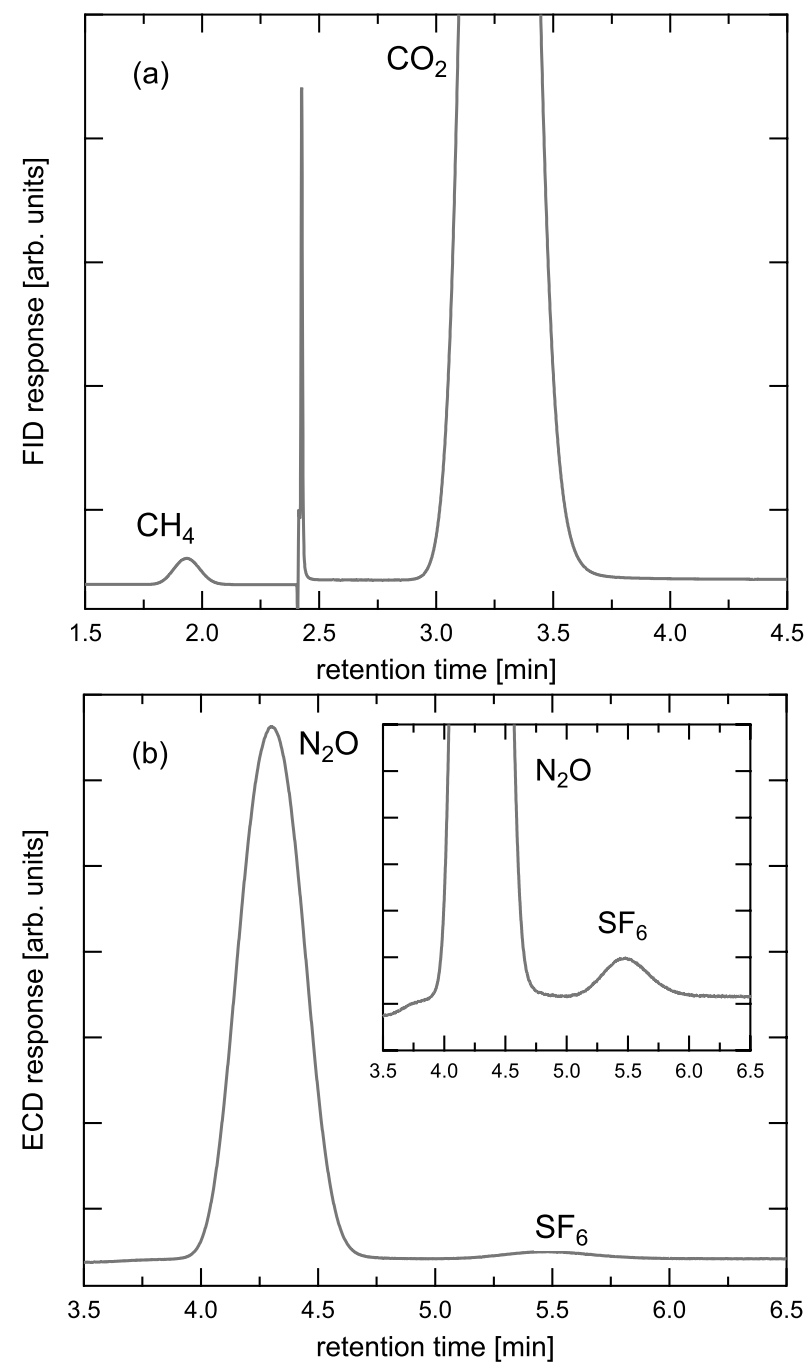

Fig. 2. Examples of gas chromatograms of the working standard obtained with the FID (a) and the ECD (b). To detect $\mathrm{CO}_{2}$ with the FID the gas flow is directed over a methanizer after the $\mathrm{CH}_{4}$ has passed. The spike in the FID chromatogram at $2.4 \mathrm{~min}$ is caused by this valve switching.

within their 1- $\sigma$ error bars for all samples and for all species measured, and no bias was observed.

The maximum water content of the re-measured samples was $225.3 \mathrm{ppm}$. This corresponds to a correction of the trace gas mixing ratio of $0.02 \%$. Taking the average precision of $0.08 \%$ that can be achieved in the measurement of $\mathrm{CO}_{2}$, a water content of a sample of $800 \mathrm{ppm}$ would be needed to be able to detect the difference in the $\mathrm{CO}_{2}$ mixing ratio that is caused by the volume effect of water in the sample flask. As the precision for the measurement of $\mathrm{CH}_{4}(0.17 \%), \mathrm{N}_{2}$ $(0.15 \%)$, and $\mathrm{SF}_{6}(1.5 \%)$ is not as good as for $\mathrm{CO}_{2}$, even higher water vapor contents of the samples would be necessary to cause a measurable difference.

\subsection{Intercomparison with other laboratories}

Whole air samples from the CARIBIC experiment were also analyzed for greenhouse gases using gas chromatography in other laboratories, namely in Heidelberg and in Jena. In 2006 altogether 55 samples from three flights were also analyzed for $\mathrm{CH}_{4}$ and $\mathrm{CO}_{2}$ at the Institute for Environmental Physics (IUP), Heidelberg (Germany). The $\mathrm{CO}_{2}$ mixing ratio in the samples varied between $376 \mathrm{ppm}$ and $387 \mathrm{ppm}$, the $\mathrm{CH}_{4} \mathrm{mix}-$ ing ratio varied between $1687 \mathrm{ppb}$ and $1911 \mathrm{ppb}$. For $\mathrm{CH}_{4}$ a slope of the correlation line of $0.98 \pm 0.02 \mathrm{ppb} / \mathrm{ppb}$ with $r^{2}=0.97$ was found. No systematic difference between the results of the two analyses was observed. For $\mathrm{CO}_{2}$ the slope was $0.89 \pm 0.05 \mathrm{ppm} / \mathrm{ppm}$ with $r^{2}=0.86$. There seemed to be better agreement for higher $\mathrm{CO}_{2}$ values than for lower ones, but due to the large scatter of the data with a maximum difference between the two analyses of $1.9 \mathrm{ppm}$ no definite conclusion can be drawn.

The data quality of the CARIBIC greenhouse gas analysis has been improved since then by optimizing gas flows and temperatures of the GC system as well as details of the calibration procedure. A more recent comparison of 14 samples from one flight with the Max Planck Institute for Biogeochemistry in Jena (Germany) took place in November 2008. In Jena all 14 samples were analyzed for $\mathrm{CH}_{4}, \mathrm{CO}_{2}, \mathrm{~N}_{2} \mathrm{O}$ and $\mathrm{SF}_{6}$ on a similar GC system but with higher precision (Jordan and Brand, 2001). Also one of the CARIBIC working standards (SIL196) was analyzed on this GC system for all four gases and in addition was analyzed with a LoFlo system (Da Costa and Steele, 1997) for $\mathrm{CO}_{2}$. The results of the GC measurements in Jena are included in the mean values given for standard SIL196 in Table 1. For all four gases the measurements on the two different systems agreed within their $1-\sigma$ errors.

The sample measurements in Jena were performed ten weeks after the analysis in Mainz. During that time the samples were circulating through four different laboratories for hydrocarbon, halocarbon and isotope analyses. After returning to Mainz successive to the measurement in Jena, 12 of the 14 samples still had enough pressure left in the canisters to allow for another greenhouse gas analysis. Repeating the measurements in Mainz after ten weeks showed agreement within the errors with the first measurement directly after the flight, with the exception of two samples that showed an increase in the $\mathrm{CO}_{2}$ mixing ratio of $0.5-0.7 \mathrm{ppm}$ after ten weeks.

In general the agreement between the results obtained in Jena and those obtained in Mainz before was good. Correlating the measured mixing ratios resulted in correlation parameters $r^{2}$ of 0.997 for $\mathrm{CH}_{4}$ (1774-1883 ppb), 0.959 for $\mathrm{CO}_{2}$ (379-385 ppm), 0.987 for $\mathrm{N}_{2} \mathrm{O}$ (315-323 ppb), and 0.653 for $\mathrm{SF}_{6}(6.40-6.69 \mathrm{ppt})$ The weaker correlation for $\mathrm{SF}_{6}$ reflects the larger scatter in the data obtained on the CARIBIC $\mathrm{GC}$ system with the absolute error ranging from $0.04 \mathrm{ppt}$ to $0.08 \mathrm{ppt}$ for this set of samples (corresponding to a relative 


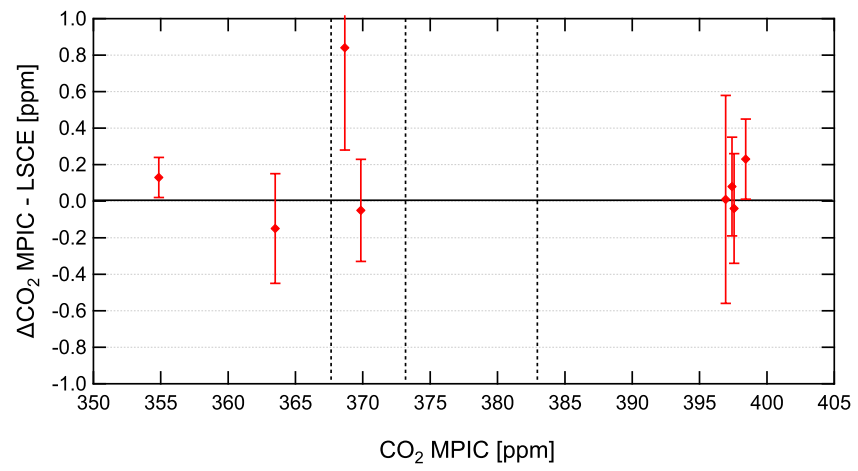

Fig. 3. Absolute difference of the analysis of $\mathrm{CO}_{2}$ mixing ratios for eight reference gases as a function of the absolute $\mathrm{CO}_{2}$ mixing ratio as determined at MPIC. The vertical dashed lines indicate the $\mathrm{CO}_{2}$ mixing ratios contained in the NOAA standards used for calibration (cf. Table 1).

error of $0.7-1.3 \%)$. All line fitting was done using the least orthogonal distance method (Cantrell, 2008).

For three of the samples the $\mathrm{CO}_{2}$ measurements in Jena resulted in somewhat higher mixing ratios than the measurements in Mainz immediately after the flight. The differences were $0.51,0.58$, and $0.71 \mathrm{ppm}$, while the uncertainties of the Mainz measurements were only $0.19,0.28$, and $0.24 \mathrm{ppm}$. Repeating the analysis in Mainz after ten weeks gave a significantly enhanced $\mathrm{CO}_{2}$ value for two of those samples and the results of the repeated measurement agreed well with the results from Jena. It is plausible that an increase of $\mathrm{CO}_{2}$ has occurred during the long storage and traveling time of the samples.

Looking at the absolute difference of the mixing ratios measured on the two different GC systems as a function of the mixing ratio as determined in Mainz, no significant dependence of the deviation on the mixing ratio could be observed for $\mathrm{CO}_{2}, \mathrm{~N}_{2} \mathrm{O}$, and $\mathrm{SF}_{6}$. With exception of $\mathrm{CH}_{4}$, for which a slope of $(0.06 \pm 0.02) \mathrm{ppb} / \mathrm{ppb}$ was found, the slopes of the absolute difference as a function of the mixing ratio were effectively zero. The mean value of the difference was $1.63 \mathrm{ppb}$ for $\mathrm{CH}_{4}, 0.09 \mathrm{ppm}$ for $\mathrm{CO}_{2} 0.009 \mathrm{ppb}$ for $\mathrm{N}_{2} \mathrm{O}$, and it was $0.04 \mathrm{ppt}$ for $\mathrm{SF}_{6}$. These values are below the average absolute error of the Mainz analysis $\left(1.86 \mathrm{ppb}\right.$ for $\mathrm{CH}_{4}$, $0.21 \mathrm{ppm}$ for $\mathrm{CO}_{2}, 0.36 \mathrm{ppb}$ for $\mathrm{N}_{2} \mathrm{O}, 0.05 \mathrm{ppt}$ for $\mathrm{SF}_{6}$ for the compared samples). This comparison confirmed the aforementioned correction to the $\mathrm{SF}_{6}$ calibration scale.

The instrument package in the CARIBIC container also includes a non-dispersive infrared device for in-situ measurements of $\mathrm{CO}_{2}$ operated by Laboratoire des Sciences du Climat et de l'Environnement (LSCE), Paris, France. The instrument is based on the Li-6262 (LI-COR) analyzer that has been modified to comply with the requirements of operation onboard an aircraft (Gibert et al., 2009). It is calibrated in flight with two standards that are calibrated at LSCE using a LoFlo $\mathrm{CO}_{2}$ analyzer (Da Costa and Steele, 1997).

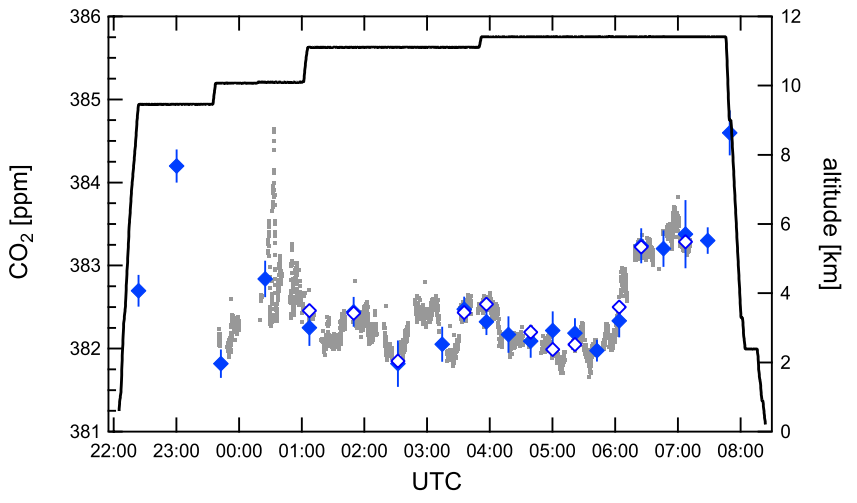

Fig. 4. Altitude (solid line) and time series of $\mathrm{CO}_{2}$ measured insitu (gray dots) and from whole air samples (closed symbols) for one CARIBIC flight. Integrals over the sampling periods have been calculated from the continuous time series (open symbols) unless the sampling coincided with a calibration event.

For five series of flights the standards used for the insitu instrument were additionally calibrated for comparison at MPIC Mainz using the CARIBIC greenhouse gas GC system. Figure 3 shows the difference of the analyses as a function of the absolute $\mathrm{CO}_{2}$ mixing ratio as determined at MPIC. With the exception of one standard the results agree within the experimental precision and no systematic difference with the absolute mixing ratio is observed.

Figure 4 compares the results from the laboratory analysis of the air samples to the in-situ measurement for one flight from Frankfurt to Guangzhou (November 2007). Shown are the flight altitude and the $\mathrm{CO}_{2}$ mixing ratio as a function of time. The in-situ data is shown as measured (gray dots) and as integrated over the sampling period for each individual whole air sample (open symbols). Five samples fall into calibration periods of the in-situ instrument so that no integral can be calculated. The in-situ instrument uses Nafion membrane tubes to dry the measured air (Brenninkmeijer et al., 2007). The data from the whole air sample analysis has been corrected for the water content of the sample as described above. The absolute difference between the sample analysis and the integrated in-situ data ranges from $0.03 \mathrm{ppm}$ to $0.3 \mathrm{ppm}$ with an average difference of $0.12 \mathrm{ppm}$. Considering an absolute error for $\mathrm{CO}_{2}$ of $0.20 \mathrm{ppm}$ for the GC measurements for this flight and a precision of $0.18 \mathrm{ppm}$ for the in-situ instrument during this flight, the results agree within their 1- $\sigma$ errors. No correlation of the mixing ratio difference with the absolute mixing ratio or with the water content of the sample has been found. This confirms the above conclusion of water vapor in the sample not having adverse effects on the $\mathrm{CO}_{2}$ measurement. 
Table 2. Coefficients $a_{1}$ to $a_{7}$ that result from fitting function 2 to the $\mathrm{CO}_{2}$ time series shown in Fig. 5 .

\begin{tabular}{lcc}
\hline & troposphere & stratosphere \\
\hline a1 & $376.30 \pm 0.82$ & $377.23 \pm 1.07$ \\
a2 & $0.35 \pm 0.07$ & $0.21 \pm 0.08$ \\
a3 & $-0.003 \pm 0.001$ & $-0.001 \pm 0.001$ \\
a4 & $2.64 \pm 0.25$ & $0.58 \pm 0.20$ \\
a5 & $0.08 \pm 0.38$ & $-0.97 \pm 0.35$ \\
a6 & $-0.69 \pm 0.30$ & $-0.25 \pm 0.31$ \\
a7 & $0.084 \pm 0.34$ & $0.43 \pm 0.25$ \\
reduced $\chi^{2}$ & 1.54 & 3.17 \\
\hline
\end{tabular}

\section{Results}

\subsection{Time series and seasonal variations of $\mathrm{CO}_{2}$}

From May 2005 through October 2008, 993 samples have been collected on flights to South America, North America, and Asia. As an example of greenhouse gas results from the CARIBIC experiment Fig. 5 shows the time series of $\mathrm{CO}_{2}$ measured from the whole air samples on flights to Asia. Plotted are monthly mean values with the error bars indicating the standard deviation of the monthly mean value. During the flights to Asia in August and in September 2008 only one sample was collected that can be attributed to the stratosphere. Therefore, no standard deviation of the mean value can be calculated for these two months. The time series includes all CARIBIC flights to the Philippines via China (21 round trips) and to India (12 round trips, sampling on 7 round trips) between November 2005 and October 2008.

As the CARIBIC aircraft frequently crosses the tropopause, the data set is divided into two subsets. The partitioning is based on the levels of $\mathrm{SF}_{6}, \mathrm{~N}_{2} \mathrm{O}$, and $\mathrm{O}_{3}$, and in addition considers potential vorticity from the ECMWF model (van Velthoven, 2009). The top panel shows the data from the extra-tropical tropopause transition layer and the lowermost stratosphere, the bottom panel shows data from the upper troposphere. In total, 684 samples have been collected on these flights that were analyzed for $\mathrm{CO}_{2}$, of which 443 were collected in the free troposphere, and 241 were collected in the tropopause region and the lowermost stratosphere.

A harmonic polynomial has been fit to the data taking into account the standard deviation of each point:

$$
\begin{aligned}
f(t)= & a_{1}+a_{2} \cdot t+a_{3} \cdot t^{2} \\
& +a_{4} \cdot \sin (2 \pi t / 12)+a_{5} \cdot \cos (2 \pi t / 12) \\
& +a_{6} \cdot \sin (4 \pi t / 12)+a_{7} \cdot \cos (4 \pi t / 12),
\end{aligned}
$$

$t$ being the time in months since January 2005 . The resulting fit coefficients and $\chi^{2}$ values are listed in Table 2. Both subsets show a similar linear increase of $a_{2}=0.35 \pm 0.07 \mathrm{ppm} / \mathrm{month}$ (troposphere) and $a_{2}=0.21 \pm 0.08 \mathrm{ppm} / \mathrm{month}$ (stratosphere). Negative values of the parameter $a_{3}$ indicate a decrease of the $\mathrm{CO}_{2}$ growth rate. However, considering the large error of the coefficients $a_{3}$ and taking into account the large values of the reduced $\chi^{2}$, no reliable conclusion on the long-term trend in the $\mathrm{CO}_{2}$ mixing ratio can be drawn. Longer time series are needed to address this question.

Between the two regimes a time shift in the seasonal cycle of about one month is observed. While the minimum $\mathrm{CO}_{2}$ mixing ratio in the troposphere is observed in September, above the tropopause it is seen in October. The maximum mixing ratio is observed in May in the troposphere and in June above the tropopause. This phase shift between the upper troposphere and the transition layer reflects the transit time of tropospheric air across the tropopause (Hoor et al., 2004; Bönisch et al., 2008). The CARIBIC results agree well with a minimum observed in early May and a maximum concentration in early September, and an amplitude of $2.2 \mathrm{ppm}$ derived from air samples collected onboard commercial aircraft in 1984 and 1985 (Nakazawa et al., 1991).

A similar, but larger, time shift of 3-4 months was observed in the tropics between the seasonal cycle at the tropopause at $\sim 16 \mathrm{~km}$ and at $\sim 19 \mathrm{~km}$ (Boering et al., 1996). At mid-latitudes, a delay of the seasonal cycle of 3 months relative to the free troposphere was observed in the lowermost stratosphere (3-7 km above the $2 \mathrm{PVU}$ surface) during the SPURT campaign (Gurk et al., 2008). During one flight, the CARIBIC aircraft often crosses the tropopause several times, but especially in summer most of the flight time is spent in the transition layer and the free stratosphere is not reached. Thus, most samples that were not from the free troposphere were sampled in the mixing layer, and the seasonal cycle shown here averages across the tropopause layer. This may explain the smaller phase shift of only month compared to three months observed during SPURT. A strong variation of the amplitude of the seasonal cycle with distance from the tropopause was also found from measurements at cruise altitudes on commercial aircraft between Japan and Europe within the CONTRAIL program (Sawa et al., 2008). In the upper troposphere, the amplitude was 6-8 ppm, above the tropopause it decreased with increasing potential temperature to $1-2 \mathrm{ppm}$.

Using the fit coefficients from Table 2, the $\mathrm{CO}_{2}$ mixing ratios have been detrended by subtracting the quadratic part of Eq. (2), and a mean seasonal cycle was calculated for both datasets. In the troposphere, the difference of the mixing ratio between the winter maximum and the subsequent summer minimum in the detrended mean seasonal cycle is $\sim 6 \mathrm{ppm}$. Above the tropopause the expected weakening of the amplitude of the seasonal cycle is observed and the difference is $\sim 2.5 \mathrm{ppm}$. Aircraft measurements at latitudes from $35^{\circ} \mathrm{N}$ to $75^{\circ} \mathrm{N}$ during the SPURT project showed that the amplitude of the seasonal cycle decreases with altitude. In the boundary layer, close to surface sources and sinks, seasonal variations were larger than in the free troposphere where an amplitude 


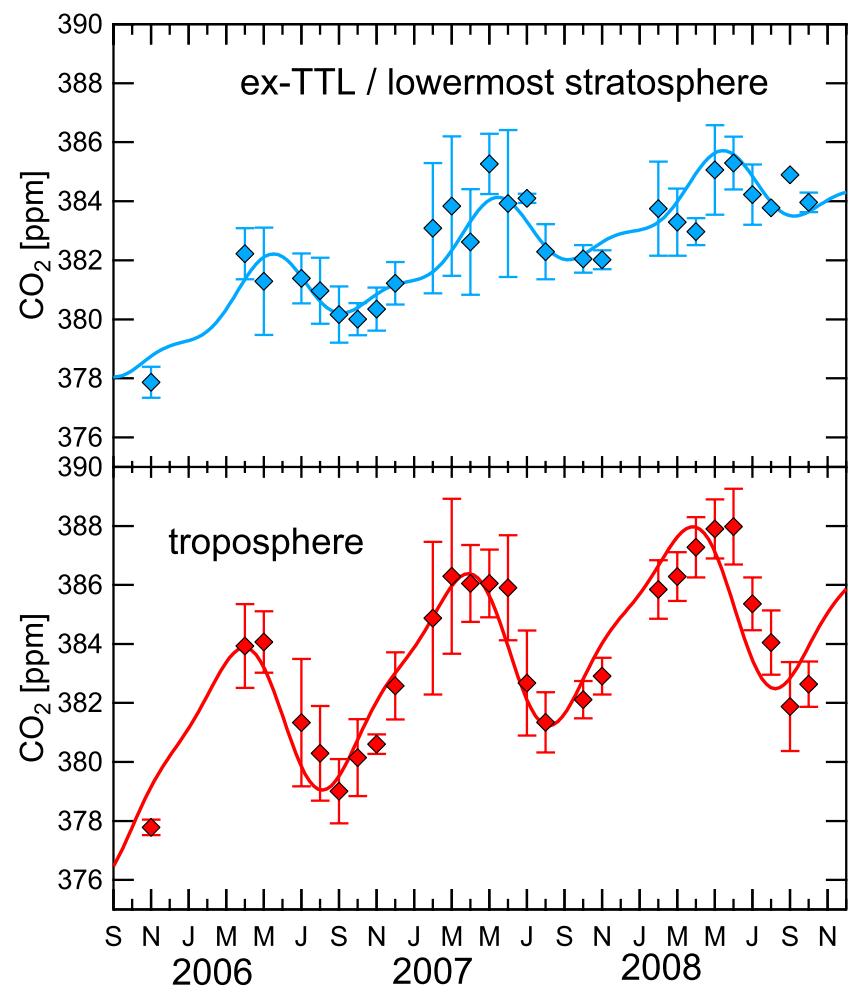

Fig. 5. $\mathrm{CO}_{2}$ time series measured during CARIBIC flights to Asia in the extra-tropical tropopause transition layer and lowermost stratosphere (upper panel) and in the upper troposphere (lower panel). The cycle above the tropopause is delayed by approximately one month. The error bars indicate the standard deviation of the monthly mean. Each month 28 samples are collected.

of $\sim 7 \mathrm{ppm}$ was observed. Above the tropopause, which acts as a barrier to vertical transport, the amplitude decreased further with a value of $\sim 3 \mathrm{ppm}$ in the lowermost stratosphere (Hoor et al., 2004; Gurk et al., 2008). The CARIBIC result is in agreement with that.

All samples collected on the flights to Asia were collected in the Northern Hemisphere within $14.4^{\circ} \mathrm{N}$ and $56.1^{\circ} \mathrm{N}$. From the detrended data a mean seasonal cycle was calculated for all tropospheric samples in five latitudinal bands of $10^{\circ}$ width. Figure 6 shows the mean seasonal cycle of the $\mathrm{CO}_{2}$ mixing ratio for all tropospheric samples (top panel) and for the four latitudinal bands from $10^{\circ}$ to $50^{\circ}$. The interval $50^{\circ}-60^{\circ}$ has been omitted due to the small number of samples. The error bars indicate the standard deviation of the monthly mean value. Also shown is a harmonic polynomial fit to the detrended mean cycle (solid lines) and the corresponding 1- $\sigma$ confidence bands (dotted lines). For fitting the polynomial the data points have been weighted with the inverse of the squared standard deviation. With the 1- $\sigma$ confidence bands of all latitudinal intervals overlapping, no significant latitudinal gradient in the amplitude of the seasonal cycle can be observed. For the stratospheric data the

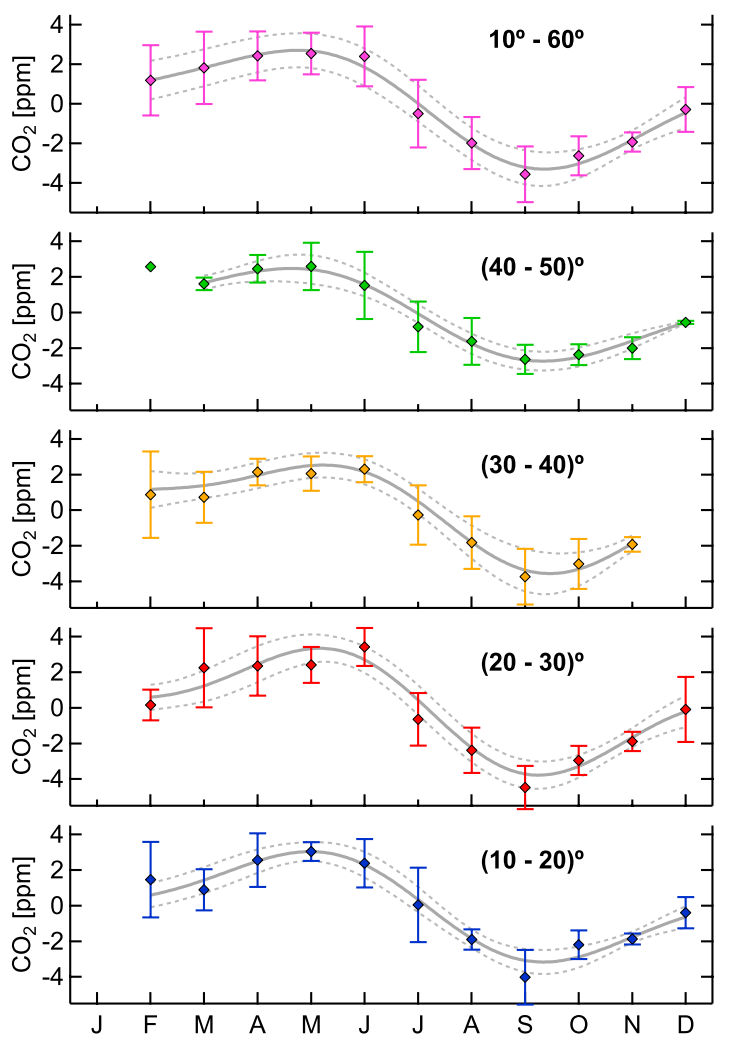

Fig. 6. Seasonal cycle of $\mathrm{CO}_{2}$ for all tropospheric samples (top panel) and for four latitudinal bands of $10^{\circ}$ width. The solid lines are harmonic polynomial fits to the detrended cycle, the dashed lines mark the $1-\sigma$ confidence bands. The error bars indicate the standard deviation of the monthly mean value.

detrended time series can be fit for the latitude bands $30^{\circ}-$ $40^{\circ}, 40^{\circ}-50^{\circ}$, and $50^{\circ}-60^{\circ}$. Again, the confidence bands for the different latitude bands overlap, so that conclusions about the latitudinal gradient are not possible. Therefore, it can't be excluded that the absence of a latitudinal gradient in the CARIBIC $\mathrm{CO}_{2}$ data may to some extent result from the time series up to now only spanning three years and flights being performed only once per month. With longer time series the quality of the harmonic polynomial fit would improve and allow conclusions on the gradient in the latitude range covered by the CARIBIC flights.

Two earlier analyses of longer time series (1994-1998 and 1993-2007) were based on flask measurements from the JAL/CONTRAIL project with samples being collected between $30^{\circ} \mathrm{N}$ and $30^{\circ} \mathrm{S}$. Similar to the CARIBIC flask sampling, sampling was performed onboard commercial aircraft at cruise altitude followed by analysis in the laboratory after removal from the aircraft (Matsueda et al., 2008; IGAC, 2007). A strong gradient in the amplitude of the seasonal cycle was found. From the 1993-2007 flask data a decrease in the amplitude of the seasonal cycle from $6 \mathrm{ppm}$ at $30^{\circ}-25^{\circ} \mathrm{N}$ 
to $3 \mathrm{ppm}$ at the equator was derived (Matsueda et al., 2002, 2008). The amplitude of $(6 \pm 2) \mathrm{ppm}$ derived for $(35 \pm 5)^{\circ} \mathrm{N}$ from the 2005-2008 CARIBIC measurements is consistent with that result. A modeling study attributed these variations in the seasonal cycle to the seasonality of the air exchange across the tropopause (Shia et al., 2006). The strongest variations in the amplitude of the seasonal cycle were observed south of $15 \mathrm{~N}$ while at more northern latitudes variations were small $(<0.5 \mathrm{ppm})$.

A study based on flask samples from biweekly flights between Japan and Australia 2000-2003 again found strong latitudinal gradients in the $\mathrm{CO}_{2}$ mixing ratio in the upper troposphere between $30^{\circ} \mathrm{N}$ and $30^{\circ} \mathrm{S}$ (Miyazaki et al., 2009). A comparison with ground based measurements and model simulations showed larger latitudinal gradients at the surface than in the upper troposphere. Modeled $\mathrm{CO}_{2}$ mixing ratios showed a smaller gradient north of $30^{\circ} \mathrm{N}$ than around the equator. Latitudinal distributions from the analysis of continuous measurements during 134 flights in April 2007 extending to $50^{\circ} \mathrm{N}$ also showed strong gradients south of $20^{\circ} \mathrm{N}$ at all altitudes up to $10 \mathrm{~km}$. However, north of $25^{\circ} \mathrm{N}$ a strong dependency on altitude with almost no latitudinal variation at altitudes of $8-10 \mathrm{~km}$ was found (Matsueda et al., 2008; Miyazaki et al., 2009). The CARIBIC observations, currently restricted to latitudes north of $14 \mathrm{~N}$, despite the limited statistics, agree with this finding.

\subsection{Spatial distribution and variability of samples}

In general, the number of stratospheric samples is lower in summer due to the higher altitude of the tropopause. In addition, for all seasons the geographical distribution of the nontropospheric samples has a strong bias towards more northern latitudes, where the tropopause is systematically lower. On the flights to Asia, $\sim 66 \%$ of all samples are collected north of $30^{\circ} \mathrm{N}$, the most northern sampling point being at $56.1^{\circ} \mathrm{N}$. While $\sim 50 \%$ of the tropospheric samples fall into that latitude band, this applies for $\sim 96 \%$ of the samples from above the tropopause. Thus, the distribution of the samples among stratosphere and troposphere has a bias with regard to season and geography that has to be taken into account when interpreting data.

Although the latitudinal distributions of sampling positions are different, there is no systematic difference observed in the $\mathrm{CO}_{2}$ time series for tropospheric and stratospheric samples that can be attributed to result from a bias due to sampling location. Thus, the time series of the two regimes averaged over the entire latitudinal range of $10^{\circ}-60^{\circ}$ may be compared e.g. with respect to the time shift. In contrast, the latitudinal distribution of the sampling locations needed to be considered when looking at $\mathrm{CO}_{2}$ data measured closer to the equator as the gradient of the seasonal amplitude becomes steeper at low latitudes (Matsueda et al., 2008; Miyazaki et al., 2009). It would also become relevant when looking at data with a steeper latitudinal gradient already at higher latitudes.

The procedure of regular sampling during a flight at cruising altitude as opposed to sampling triggered by certain events, is supposed to ensure representativeness of the samples and exclude biases. Thus the question arises how representative the CARIBIC samples are for background air. The following statistics includes all samples that were analyzed for greenhouse gases, 849 samples in total. This includes 28 flights into or in the Southern Hemisphere.

First, the data set was again divided into purely tropospheric samples and those that have experienced stratospheric influence. The latter usually contain air from the extra-tropical transition layer, and very few are from the lowermost stratosphere. For each monthly round trip the median $\mathrm{CO}_{2}$ mixing ratio was calculated for the stratospheric and the tropospheric subset and for each sample the deviation of the measured $\mathrm{CO}_{2}$ mixing ratio from that monthly median. Figure 7 shows the distribution of the deviation from the monthly median for the tropospheric (a) and the stratospheric (b) sample subsets. Referring to the deviation from the monthly median for each sample ensures that seasonal variations and the continuous rise of $\mathrm{CO}_{2}$ do not affect the distribution. If sampling in pollution plumes frequently happened, a considerable number of samples should contain high amounts of $\mathrm{CO}_{2}$, whereas sampling of only background air should result in a near Gaussian distribution. Sampling during CARIBIC flights is done in different locations, and spatial variations of the $\mathrm{CO}_{2}$ mixing ratio result in the distribution deviating from a Gaussian.

Averaging the difference from the monthly median over all samples, the standard deviation is $\sigma \sim 1.5 \mathrm{ppm}$ for both distributions. In the troposphere, $\sim 94.3 \%$ of the samples are within an interval of $\pm 3 \mathrm{ppm}$ from the median, $1.9 \%$ are more than 3 ppm lower than the median, and $3.8 \%$ are more than 3 ppm higher. In the stratospheric data subset, containing 307 out of 849 samples, $~ 91.1 \%$ of the samples are within $\pm 3 \mathrm{ppm}$ around the monthly median, $7.6 \%$ are more than 3 ppm lower, and $1.3 \%$ (4 samples) are more than 3 ppm higher than the median value. Comparing with the monthly mean mixing ratio results in similar values, indicating that the mean value is not strongly influenced by extreme values such as plumes.

Although the percentage of samples that fall within the $\pm 2 \sigma$ interval is close to what is expected for a Gaussian (94.4\%), the distribution deviates from a normal distribution and is not symmetric. Moreover, $77 \%$ (troposphere) and $\sim 73 \%$ (stratosphere) of the samples fall into the $\pm 1.5 \mathrm{ppm}$ interval around the median, which is a higher percentage than expected for a normal distribution $(68.3 \%$ falling into the $\pm 1 \sigma$ interval). The low number of samples with $\mathrm{CO}_{2}$ mixing ratios significantly above the median implies, that the influence of plumes on the distribution is low and the CARIBIC air samples do represent background air for both, the troposphere and the extra-tropical tropopause transition layer. 
With a longer sampling time the probability of sampling air from pollution plumes would increase, but the sample would contain a mixture of plume air and background air. For studies of plumes the initially intended triggered operation of the air sampler would be preferable. The current mode of taking samples evenly distributed over the flight time yields a better representation of atmospheric background concentrations. The question of how different types of air masses are represented in the CARIBIC data has recently been addressed in a more general approach using cluster analysis (Köppe et al., 2009).

\subsection{Flights Frankfurt $\leftrightarrow$ Guangzhou $\leftrightarrow$ Manila}

Figure 8 shows an overview of the greenhouse gas results for a round trip from Frankfurt (Germany) to Manila (Philippines) and back via Guangzhou (China) that took place in February 2008. The top panel shows the altitude of the aircraft as a function of time. Markers along the altitude profile show where air samples have been collected. Also included is the time series of potential vorticity (PV) in PVunits (PVU $\hat{=} 10^{-6} \mathrm{Km}^{2} \mathrm{~kg}^{-1} \mathrm{~s}^{-1}$ ) as a measure of stratospheric air. High values of PV exceeding 3.5 PVU, indicating stratospheric air, have been encountered on the long-distance flight between Frankfurt and Guangzhou. In the tropics, the tropopause is higher, and during the two short flight legs between Guangzhou and Manila PV is always below 1 PVU. The middle and bottom panels display the time series of $\mathrm{CH}_{4}$ and $\mathrm{CO}_{2}$ (middle) and of $\mathrm{N}_{2} \mathrm{O}$ and $\mathrm{SF}_{6}$ (bottom). All four gases had lower mixing ratios in the stratosphere and were positively correlated in the troposphere and in the stratosphere.

Figure 9a shows the correlations between $\mathrm{CH}_{4}$ and $\mathrm{CO}_{2}$ for the flight in February 2008 (circles) and for a flight on the same route that was conducted in August 2007 (triangles). While the winter flight exhibits a rather compact positive correlation between the two gases, the summer data look rather different, and the relation turns into an anti-correlation that is, however, less compact. In winter, the positive correlation between $\mathrm{CH}_{4}$ and $\mathrm{CO}_{2}$ is a typical feature during the CARIBIC flights at northern mid-latitudes. It can be understood as a consequence of the seasonal cycle of atmospheric $\mathrm{CO}_{2}$ with mixing ratios increasing during winter and lower values in summer. The air encountered in winter above the tropopause is slightly older and thus preserves the lower $\mathrm{CO}_{2}$ concentration of the preceding summer (Hoor et al., 2004; Bönisch et al., 2008). In summer, tropospheric $\mathrm{CO}_{2}$ levels decrease strongly due to uptake of $\mathrm{CO}_{2}$ by vegetation and oceans. The seasonal cycle of $\mathrm{CH}_{4}$ in the Northern Hemisphere is more complex (Dlugokencky et al., 1994). While the destruction of $\mathrm{CH}_{4}$ due to reaction with $\mathrm{OH}$ is expected to be stronger in summer, source strengths also strongly vary with the seasons. During the flight in August, $\mathrm{CH}_{4}$ tended to be higher than during the flight in February, and the positive correlation observed in winter is lost. A possible reason
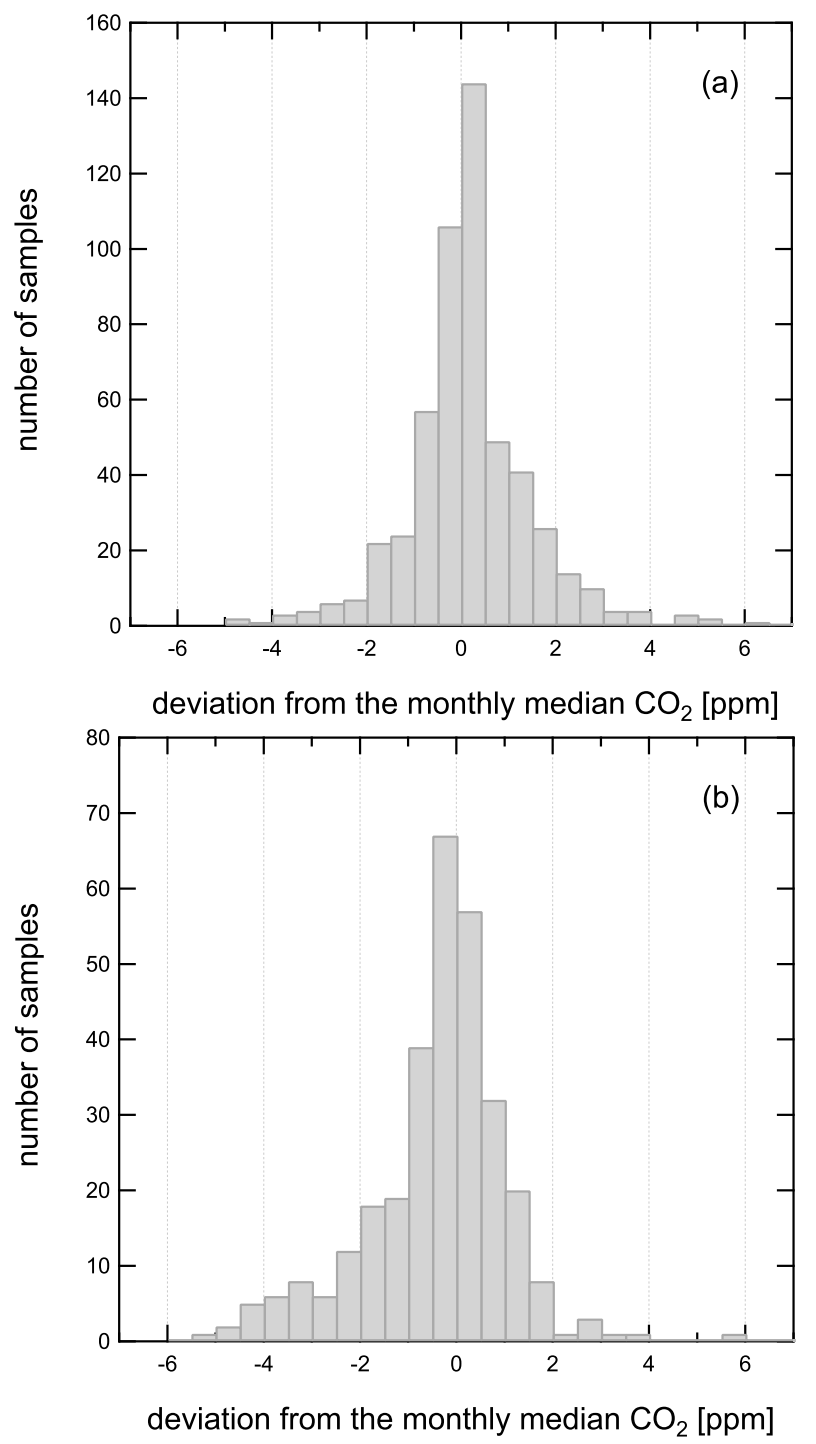

Fig. 7. Distribution of the $\mathrm{CO}_{2}$ mixing ratio around the monthly median value for samples collected in the upper troposphere (a) and above the tropopause (b). Only few samples have mixing ratios exceeding the monthly median by more than $3 \mathrm{ppm}$, which implies that the samples are largely representative for background air.

for the higher $\mathrm{CH}_{4}$ mixing ratio in summer may be enhanced emissions of $\mathrm{CH}_{4}$ from rice paddies, wetlands and landfills (Bogner and Spokas, 1993; Chen and Prinn, 2006; Khalil and Butenhoff, 2008) and enhanced convective transport into the upper troposphere (Park et al., 2004). While in August $\mathrm{CH}_{4}$ is still lower at higher PV values (closed symbols in Fig. 9), this is now different for $\mathrm{CO}_{2}$. The tropopause region and lowermost stratosphere still contain air that has been transported across the tropopause before. This results in the observed shift in the seasonal cycle (Hoor et al., 2004), and this region preserves the still elevated $\mathrm{CO}_{2}$ mixing ratios of early summer. High PV now coincides with higher $\mathrm{CO}_{2}$, while this was reversed in winter. 


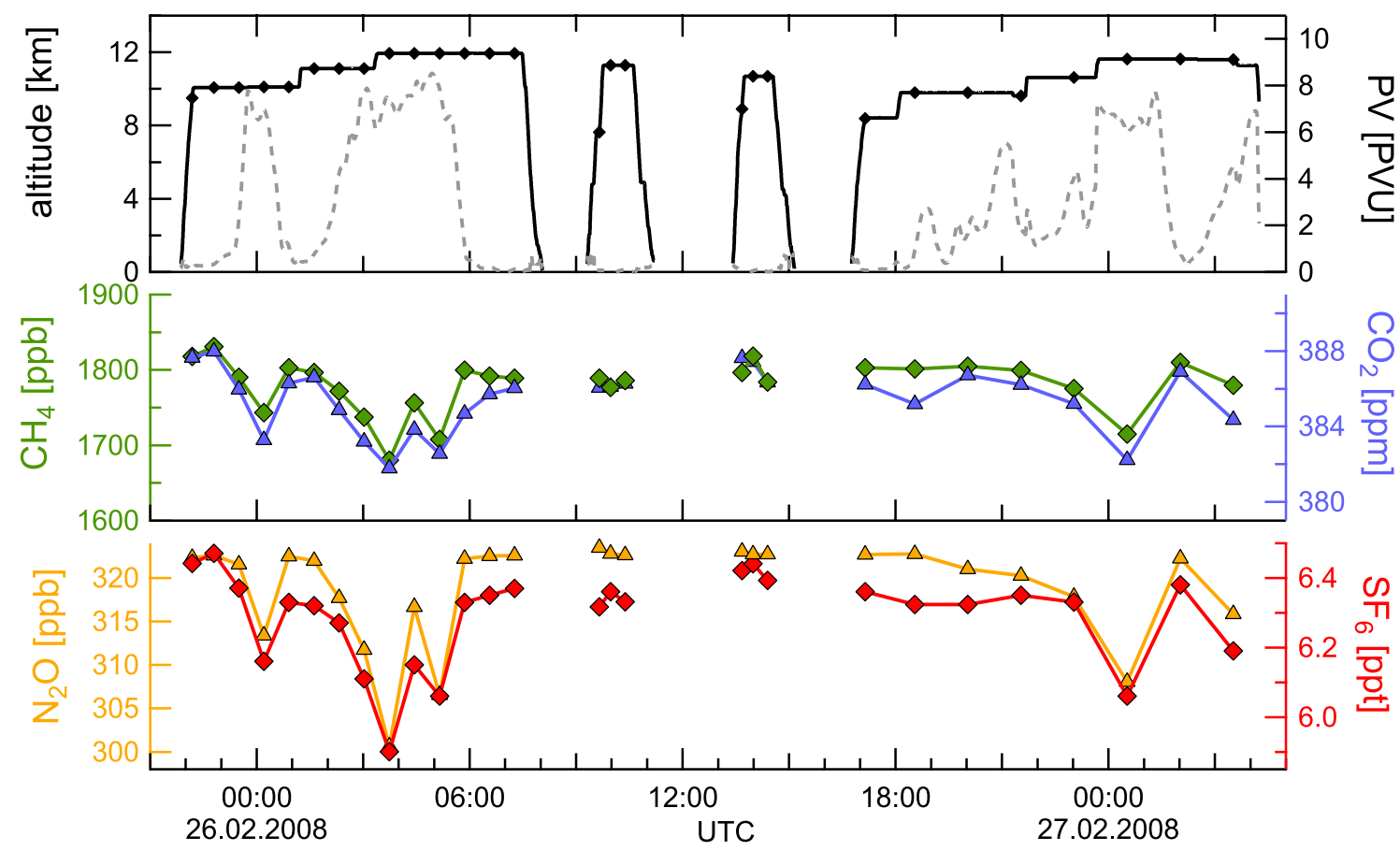

Fig. 8. Overview of CARIBIC flights Frankfurt $\leftrightarrow$ Guangzhou $\leftrightarrow$ Manila on 25, 26, 27 February 2008. Top panel: Altitude (black solid line) and PV (gray dotted line), middle panel: $\mathrm{CH}_{4}$ (green diamonds) and $\mathrm{CO}_{2}$ (blue triangles) mixing ratios, bottom panel: $\mathrm{N}_{2} \mathrm{O}$ (orange triangles) and $\mathrm{SF}_{6}$ mixing ratios (red diamonds).

Figure $9 \mathrm{~b}$ shows the correlations between $\mathrm{N}_{2} \mathrm{O}$ and $\mathrm{SF}_{6}$ for the same flights. $\mathrm{N}_{2} \mathrm{O}$ is stable and well-mixed in the troposphere. It gets photochemically destroyed in the stratosphere which leads to a strong gradient across the tropopause (Ko et al., 1991; Kaiser et al., 2006). SF6 also shows a crosstropopause gradient, because it is emitted from ground based sources and does not have any tropospheric sinks (Maiss and Levin, 1994). During both flights, lower $\mathrm{N}_{2} \mathrm{O}$ and $\mathrm{SF}_{6}$ values coincide with high values of $\mathrm{PV}$, and a positive correlation between the two gases is observed. In winter, when the tropopause height is lower, the CARIBIC aircraft with its cruising altitude being independent of season penetrates deeper into the stratosphere than during summer. Therefore, the lowest mixing ratios of $\mathrm{N}_{2} \mathrm{O}$ and $\mathrm{SF}_{6}$ are encountered in February. For PV>3 PVU (closed symbols) the correlation seems to be steeper in August than in February, and at the lowest $\mathrm{SF}_{6}$ mixing ratios a wider range of $\mathrm{N}_{2} \mathrm{O}$ values is observed, with higher values in August. This difference most likely arises from the larger scatter and the small number of data points at high PV. Looking at the correlation of both gases with PV, no difference between the two months is seen, but the correlation becomes less compact at higher PV values.

In the troposphere (open symbols), a positive correlation of $\mathrm{N}_{2} \mathrm{O}$ and $\mathrm{SF}_{6}$ is observed in August and in February with similar slopes (black lines). In general, the amplitude of the seasonal cycle of tracers was found to decrease with increasing lifetime (Nevison et al., 2004), so that for $\mathrm{SF}_{6}$ only a very weak cycle is to be expected. Emissions of $\mathrm{SF}_{6}$ occur independent of season, and its seasonal cycle is only related to atmospheric transport. Observations at ground stations show strong variations of the amplitude between $0 \mathrm{ppt}$ and $0.17 \mathrm{ppt}$ depending on the altitude and the distance to sources. At the remote station at Mauna Loa $\left(\mathrm{MLO}, 19.53^{\circ} \mathrm{N}, 155.58^{\circ} \mathrm{W}\right)$ a $0 \mathrm{ppt}$ seasonal cycle was observed at $3397 \mathrm{~m}$ altitude (Gloor et al., 2007). During the two CARIBIC flights shown here, tropospheric values of $\mathrm{SF}_{6}$ in February 2008 were higher than in August 2007 by about 0.15 ppt. This is consistent with the average increase rate of $\sim 0.21 \mathrm{ppt} \mathrm{yr}^{-1}$ (Solomon et al., 2007), and it is unlikely that this increase is related to seasonal changes.

$\mathrm{N}_{2} \mathrm{O}$ has a weak seasonal cycle in the troposphere with a summer minimum and an amplitude in the Northern Hemisphere of about $0.8 \mathrm{ppb}$ at the surface (Liao et al., 2004; Nevison et al., 2007). It was suggested that this is related to transport of $\mathrm{N}_{2} \mathrm{O}$ depleted air from the stratosphere into the troposphere (Morgan et al., 2004; Nevison et al., 2004). Tropospheric mixing ratios are slowly increasing at a rate of $\sim 0.7 \mathrm{ppb} \mathrm{yr}^{-1}$ (Solomon et al., 2007). The small horizontal shift of $\sim 0.6 \mathrm{ppb}$ observed between the tropospheric $\mathrm{N}_{2} \mathrm{O}$ mixing ratios in August and in February could partly be caused by this increase and partly by the seasonal cycle. 


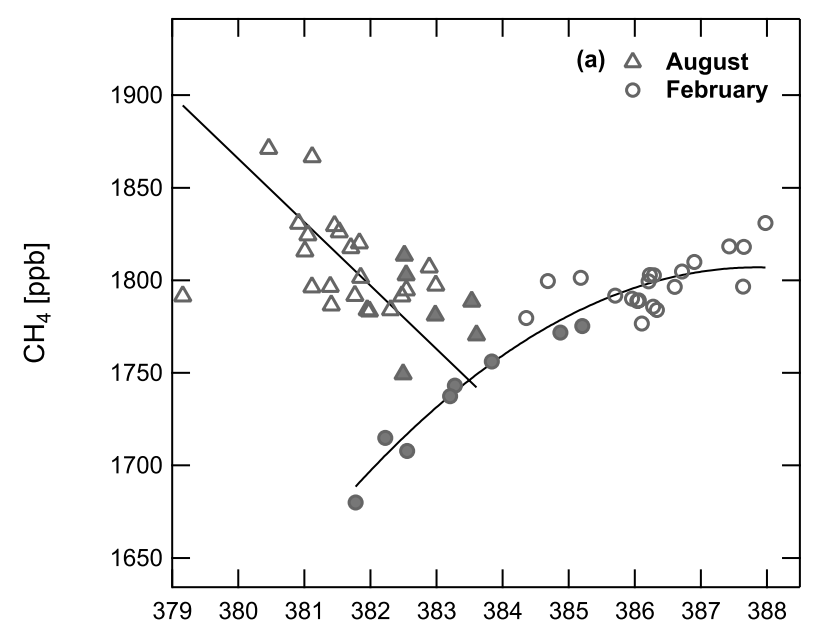

ing routine flights. After a flight, 28 pressurized sample flasks are analyzed on a GC system in the laboratory. The air sampling system and the greenhouse gas analysis of air samples have been reliably working since 2005 . Good results have been obtained in comparisons of the sample analysis with other laboratories and no systematic differences were encountered for all measured gases within the experimental precision.

Of the four gases $\mathrm{CO}_{2}$ was used as a tracer for pollution plumes because it can be measured with the highest precision. The distribution of mixing ratios around the monthly median imply that the samples collected are representative of background air in the free troposphere at mid-latitudes and in the tropics and in the extra-tropical UT/LS region. The seasonal cycle of $\mathrm{CO}_{2}$ has been analyzed separately for the upper troposphere and the tropopause region. A time shift of about one month due to transport across the tropopause has been found, reflecting the transport time of upper tropospheric air masses across the tropopause. In addition to this delay, the amplitude of the seasonal cycle is weakened from $6 \mathrm{ppm}$ in the upper troposphere to $2.5 \mathrm{ppm}$ in the tropopause region. These findings are in agreement with earlier results. Between $30^{\circ} \mathrm{N}$ and $56^{\circ} \mathrm{N}$ no variation of the amplitude of the seasonal cycle has been found which also is in agreement with other observations in the upper troposphere. However, the possibilities of statistical analyses are still limited due to the restriction of the data set to three years with monthly flights and the limited number of data points per flight. Extending the analysis by including the continuous $\mathrm{CO}_{2}$ measurements that are also part of the project may in the future allow to obtain statistically more significant results.

Two individual return flights from Germany to East Asia in August 2007 and February 2008 are discussed as examples. All four gases are correlated during these flights. They show a distinct positive correlation between $\mathrm{CH}_{4}$ and $\mathrm{CO}_{2}$ in boreal winter that switches into an anti-correlation in sum-

Fig. 9. Correlation between $\mathrm{CH}_{4}$ and $\mathrm{CO}_{2}$ (a) and between $\mathrm{N}_{2} \mathrm{O}$ and $\mathrm{SF}_{6}$ (b) for two CARIBIC flights, one in August 2007 (triangles) and one in February 2008 (circles). A straight line and a third order polynomial have been included in (a), two straight lines in (b) to illustrate the discussed correlations. While in winter a pronounced positive correlation can be observed for $\mathrm{CH}_{4}$ and $\mathrm{CO}_{2}$, this behavior changes in summer. Samples taken at high PV values $>3 \mathrm{PVU}$ are marked by filled symbols, tropospheric samples by open symbols.

\section{Summary and conclusions}

The monthly operation of the CARIBIC system enables detailed systematic observations of greenhouse gases in the upper troposphere and the lowermost stratosphere. While the instrument package comprises many real-time measurements of atmospheric compounds, $\mathrm{CH}_{4}, \mathrm{CO}_{2}, \mathrm{~N}_{2} \mathrm{O}$ and $\mathrm{SF}_{6}$ are simultaneously measured in air samples that are collected from aboard a commercial Lufthansa passenger aircraft durmer, reflecting the seasonal changes in atmospheric $\mathrm{CO}_{2}$ and $\mathrm{CH}_{4}$ levels. In contrast, the correlation between $\mathrm{N}_{2} \mathrm{O}$ and $\mathrm{SF}_{6}$ is positive during both months. The measurements are consistent with the continuous increase observed for these two tracers.

CARIBIC is continuing the monthly flights of its instrument container including the collection of air samples providing a continuously growing data set. Longer time series will allow for more detailed statistical analyses in the future. In addition, the repeated simultaneous accurate measurements will provide useful data for model comparisons of several species at the same time. Beyond understanding the observations made during single flights, it is also hoped that the CARIBIC greenhouse gas measurements contribute to global long-term monitoring complementing the information collected by ground-based networks and other aircraft measurements. 
Acknowledgements. We gratefully acknowledge the support from all CARIBIC partners, from Lufthansa and from Lufthansa Technik. The GC system has initially been set up by D. Worthy (Env. Canada). Meteorological analyses are done by P. van Velthoven (KNMI). Data for comparisons have kindly been provided by M. Schmidt (LSCE), A. Jordan (MPI Jena), and I. Levin (IUP Heidelberg). E. Scheel (IMK) provided valuable input during a GAW $\mathrm{N}_{2} \mathrm{O}$ audit. NOAA-CMDL supplied standards and valuable advice. We acknowledge the support of the European Commission through the GEOmon (Global Earth Observation and Monitoring) Integrated Project under the 6th Framework Program (contract number FP6-2005-Global-4-036677).

The service charges for this open access publication have been covered by the Max Planck Society.

Edited by: D. Riemer

\section{References}

Assonov, S., Taylor, P., and Brenninkmeijer, C. A. M.: A system for high quality $\mathrm{CO}_{2}$ isotope analysis of air samples collected by the CARIBIC Airbus A340-600, Rapid Comun. Mass. Sp., 23, 1347-1363, doi:10.1002/rcm.4008, 2009.

Baker, A. K., Slemr, F., and Brenninkmeijer, C. A. M.: Analysis of non-methane hydrocarbons in air samples collected aboard the CARIBIC passenger aircraft, Atmos. Meas. Tech. Discuss., submitted, 2009.

Boering, K. A., Wofsy, S. C., Daube, B. C., Schneider, H. R., Loewenstein, M., Podolske, J. R., and Conway, T. J.: Stratospheric Mean Ages and Transport Rates from Observations of Carbon Dioxide and Nitrous Oxide, Science, 274, 1340-1343, 1996.

Bogner, J. and Spokas, K.: Landfill $\mathrm{CH}_{4}$ : Rates, fates, and role in global carbon cycle, Chemosphere, 26, 369-386, doi:10.1016/ 0045-6535(93)90432-5, 1993.

Bönisch, H., Engel, A., Curtius, J., Birner, T., and Hoor, P.: Quantifying transport into the lowermost stratosphere using simultaneous in-situ measurements of $\mathrm{SF}_{6}$ and $\mathrm{CO}_{2}$, Atmos. Chem. Phys. Discuss., 8, 21229-21264, 2008,

http://www.atmos-chem-phys-discuss.net/8/21229/2008/.

Brenninkmeijer, C. A. M., Slemr, F., Koeppel, C., Scharffe, D. S., Pupek, M., Lelieveld, J., Crutzen, P., Zahn, A., Sprung, D., Fischer, H., Hermann, M., Reichelt, M., Heintzenberg, J., Schlager, H., Ziereis, H., Schumann, U., Dix, B., Platt, U., Ebinghaus, R., Martinsson, B., Ciais, P., Filippi, D., Leuenberger, M., Oram, D., Penkett, S., van Velthoven, P., and Waibel, A.: Analyzing Atmospheric Trace Gases and Aerosols Using Passenger Aircraft, EOS Transactions, 86, 77-82, doi:10.1029/2005EO080001, 2005.

Brenninkmeijer, C. A. M., Crutzen, P., Boumard, F., Dauer, T., Dix, B., Ebinghaus, R., Filippi, D., Fischer, H., Franke, H., Frieß, U., Heintzenberg, J., Helleis, F., Hermann, M., Kock, H. H., Koeppel, C., Lelieveld, J., Leuenberger, M., Martinsson, B. G., Miemczyk, S., Moret, H. P., Nguyen, H. N., Nyfeler, P., Oram, D., O’Sullivan, D., Penkett, S., Platt, U., Pupek, M., Ramonet, M., Randa, B., Reichelt, M., Rhee, T. S., Rohwer, J., Rosenfeld, K., Scharffe, D., Schlager, H., S chumann, U., Slemr, F., Sprung, D., Stock, P., Thaler, R., Valentino, F., van Velthoven, P., Waibel, A., Wandel, A., Waschitschek, K., Wiedensohler, A., Xueref-Remy,
I., Zahn, A., Zech, U., and Ziereis, H.: Civil Aircraft for the regular investigation of the atmosphere based on an instrumented container: The new CARIBIC system, Atmos. Chem. Phys., 7, 4953-4976, 2007, http://www.atmos-chem-phys.net/7/4953/2007/.

Buck, A. L.: New Equations for Computing Vapor Pressure and Enhancement Factor, J. Appl. Meteorol., 20, 1527-1532, 1981.

Butenhoff, C. and Khalil, M.: Correction for water vapor in the measurement of atmospheric trace gases, Chemosphere, 47, 823-836, 2002.

Cantrell, C. A.: Technical Note: Review of methods for linear leastsquares fitting of data and application to atmospheric chemistry problems, Atmos. Chem. Phys., 8, 5477-5487, 2008, http://www.atmos-chem-phys.net/8/5477/2008/.

Chen, Y.-H. and Prinn, R. G.: Estimation of atmospheric methane emissions between 1996 and 2001 using a three-dimensional global chemical transport model, J. Geophys. Res., 111, 10307, doi:10.1029/2005JD006058, 2006.

Da Costa, G. and Steele, L. P.: A low-flow analyser system for making measurements of atmospheric $\mathrm{CO}_{2}$, in: Report of the Ninth WMO Meeting of Experts on Carbon Dioxide Concentration and Related Tracer Measurement Techniques, edited by Francey, R. no. 132 in Global Atmospheric Watch Report Series, p. 1620 , World Meteorological Organization, Geneva, 1997.

Dlugokencky, E. J., Steele, L. P., Lang, P. M., and Masarie, K. A.: The growth rate and distribution of atmospheric methane, J. Geophys. Res., 99, 17021-17044, doi:10.1029/94JD01245, 1994.

Dlugokencky, E. J., Myers, R. C., Lang, P. M., Masarie, K. A., Crotwell, A. M., Thoning, K. W., Hall, B. D., Elkins, J. W., and Steele, L. P.: Conversion of NOAA atmospheric dry air $\mathrm{CH}_{4}$ mole fractions to a gravimetrically prepared standard scale, J. Geophys. Res., 110, 18306, doi:10.1029/2005JD006035, 2005.

Engel, A., Bönisch, H., Brunner, D., Fischer, H., Franke, H., Günther, G., Gurk, C., Hegglin, M., Hoor, P., Königstedt, R., Krebsbach, M., Maser, R., Parchatka, U., Peter, T., Schell, D., Schiller, C., Schmidt, U., Spelten, N., Szabo, T., Weers, U., Wernli, H., Wetter, T., and Wirth, V.: Highly resolved observations of trace gases in the lowermost stratosphere and upper troposphere from the Spurt project: an overview, Atmos. Chem. Phys., 6, 283-301, 2006, http://www.atmos-chem-phys.net/6/283/2006/.

Fischer, H., Wienhold, F. G., Hoor, P., Bujok, O., Schiller, C., Siegmund, P., Ambaum, M., Scheeren, H. A., and Lelieveld, J.: Tracer correlations in the northern high latitude lowermost stratosphere: Influence of cross-tropopause mass exchange, Geophys. Res. Lett., 27, 97-100, doi:10.1029/1999GL010879, 2000.

Fraser, P. J., Oram, D. E., Reeves, C. E., Penkett, S. A., and McCulloch, A.: Southern hemispheric halon trends (1978-1998) and global halon emissions, J. Geophys. Res., 104, 15985-16000, doi:10.1029/1999JD900113, 1999.

Gibert, F., Joly, L., Xuéref-Rémy, I., Schmidt, M., Royer, A., Flamant, P. H., Ramonet, M., Parvitte, B., Durry, G., and Zéninari, V.: Inter-comparison of $2 \mu \mathrm{m}$ Heterodyne Differential Absorption Lidar, Laser Diode Spectrometer, LICOR NDIR analyzer and flasks measurements of near-ground atmospheric $\mathrm{CO}_{2}$ mixing ratio, Spectrochim. Acta A, 71, 1914-1921, doi:10.1016/j. saa.2008.07.010, 2009.

Gloor, M., Dlugokencky, E., Brenninkmeijer, C., Horowitz, L., Hurst, D. F., Dutton, G., Crevoisier, C., Machida, T., and Tans, 
P.: Three-dimensional $\mathrm{SF}_{6}$ data and tropospheric transport simulations: Signals, modeling accuracy, and implications for inverse modeling, J. Geophys. Res., 112, 15112, doi:10.1029/ 2006JD007973, 2007.

Gurk, Ch., Fischer, H., Hoor, P., Lawrence, M. G., Lelieveld, J., and Wernli, H.: Airborne in-situ measurements of vertical, seasonal and latitudinal distributions of carbon dioxide over Europe, Atmos. Chem. Phys., 8, 6395-6403, 2008, http://www.atmos-chem-phys.net/8/6395/2008/.

Hall, B. D., Dutton, G. S., and Elkins, J. W.: The NOAA nitrous oxide standard scale for atmospheric observations, J. Geophys. Res., 112, 9305, doi:10.1029/2006JD007954, 2007.

Holton, J. R., Haynes, P. H., McIntyre, M. E., Douglass, A. R., Rood, R. B., and Pfister, L.: Stratosphere-troposphere exchange, Rev. Geophys., 33, 403-439, doi:10.1029/95RG02097, 1995.

Hoor, P., Gurk, C., Brunner, D., Hegglin, M. I., Wernli, H., and Fischer, H.: Seasonality and extent of extratropical TST derived from in-situ CO measurements during SPURT, Atmos. Chem. Phys., 4, 1427-1442, 2004,

http://www.atmos-chem-phys.net/4/1427/2004/.

IGAC: Special Issue on routine measurements from mobile platforms (CARIBIC, MOZAIC, CONTRAIL, TROICA, cargo ships), IGAC Newsletter, pp. 2-30, 2007.

Jordan, A. and Brand, W. A.: Trace gas measurement and quality assurance at the MPI for Biogeochemistry, in: Report to the 11th WMO/IAEA Meeting of Experts on $\mathrm{CO}_{2}$ and related tracer measurement techniques, Annex B6, pp. 38-42, 2001.

Kaiser, J., Engel, A., Borchers, R., and Röckmann, T.: Probing stratospheric transport and chemistry with new balloon and aircraft observations of the meridional and vertical $\mathrm{N}_{2} \mathrm{O}$ isotope distribution, Atmos. Chem. Phys., 6, 3535-3556, 2006, http://www.atmos-chem-phys.net/6/3535/2006/.

Khalil, M. A. K. and Butenhoff, C. L.: Spatial variability of methane emissions from rice fields and implications for experimental design, J. Geophys. Res., 113, G00A09, doi:10.1029/ 2007JG000517, 2008.

Ko, M. K. W., Sze, N. D., and Weisenstein, D. K.: Use of satellite data to constrain the model-calculated atmospheric lifetime for $\mathrm{N}_{2} \mathrm{O}$ - Implications for other trace gases, J. Geophys. Res., 96, 7547-7552, doi:10.1029/91JD00273, 1991.

Köppe, M., Hermann, M., Brenninkmeijer, C. A. M., Heintzenberg, J., Schlager, H., Schuck, T., Slemr, F., Sprung, D., van Velthoven, P. F. J., Wiedensohler, A., Zahn, A., and Ziereis, H.: Origin of aerosol particles in the mid latitude and subtropical upper troposphere and lowermost stratosphere from cluster analysis of CARIBIC data, Atmos. Chem. Phys. Discuss., 9, 13523-13567, 2009, http://www.atmos-chem-phys-discuss.net/9/13523/2009/.

Liao, T., Camp, C. D., and Yung, Y. L.: The seasonal cycle of $\mathrm{N}_{2} \mathrm{O}$, Geophys. Res. Lett., 31, 17108, doi:10.1029/2004GL020345, 2004.

Maiss, M. and Brenninkmeijer, C.: Atmospheric $\mathrm{SF}_{6}$ : Trends, Sources, and Prospects observed in the atmosphere, Environ. Sci. Technol., 32, 3077-3086, 1998.

Maiss, M. and Levin, I.: Global increase of $\mathrm{SF}_{6}$ observed in the atmosphere, Geophys. Res. Lett., 21, 569-572, doi:10.1029/ 94GL00179, 1994.

Matsueda, H., Inoue, H., and Ishii, M.: Aircraft observation of carbon dioxide at $8-13 \mathrm{~km}$ altitude over the western Pacific from
1993 to 1999, Tellus B, 54, 1-21, 2002.

Matsueda, H., Machida, T., Sawa, Y., Nakagawa, Y., Hirotani, K., Ikeda, H., Kondo, N., and Goto, K.: Evaluation of atmospheric $\mathrm{CO}_{2}$ measurements from new flask air sampling of JAL airliner observations, Pap. in Meteorol. Geophys., 59, 1-17, 2008.

Miyazaki, K., Machida, T., Patra, P. K., Iwasaki, T., Sawa, Y., Matsueda, H., and Nakazawa, T.: Formation mechanisms of latitudinal $\mathrm{CO}_{2}$ gradients in the upper troposphere over the subtropics and tropics, J. Geophys. Res., 114, 3306, doi:10.1029/ 2008JD010545, 2009.

Morgan, C. G., Allen, M., Liang, M. C., Shia, R. L., Blake, G. A., and Yung, Y. L.: Isotopic fractionation of nitrous oxide in the stratosphere: Comparison between model and observations, J. Geophys. Res., 109, D04305, doi:10.1029/2003JD003402, 2004.

Mosier, A., Kroeze, C., Nevison, C., Oenema, O., Seitzinger, S., and van Cleemput, O.: Closing the global $\mathrm{N}_{2} \mathrm{O}$ budget: nitrous oxide emissions through the agricultural nitrogen cycle, Nutr. Cycl. Agrecosyst., 52, 225-248, doi:10.1023/A: $1009740530221,1998$.

Nakazawa, T., Miyashita, K., Aoki, S., and Tanaka, M.: Temporal and spatial variations of upper tropospheric and lower stratospheric carbon dioxide, Tellus B, 43, 106-117, 1991.

Nevison, C. D., Kinnison, D. E., and Weiss, R. F.: Stratospheric influences on the tropospheric seasonal cycles of nitrous oxide and chlorofluorocarbons, Geophys. Res. Lett., 31, 20103, doi: 10.1029/2004GL020398, 2004.

Nevison, C. D., Mahowald, N. M., Weiss, R. F., and Prinn, R. G.: Interannual and seasonal variability in atmospheric $\mathrm{N}_{2} \mathrm{O}$, Global Biogeochem. Cycles, 21, B3017, doi:10.1029/2006GB002755, 2007.

O'Sullivan, D. A.: Temporal and spatial variability of halogenated compounds and other trace gases, $\mathrm{PhD}$ thesis, University of East Anglia, 2007.

Park, M., Randel, W. J., Kinnison, D. E., Garcia, R. R., and Choi, W.: Seasonal variation of methane, water vapor, and nitrogen oxides near the tropopause: Satellite observations and model simulations, J. Geophys. Res., 109, 3302, doi:10.1029/ 2003JD003706, 2004.

Rhee, T., Mak, J., Röckmann, T., and Brenninkmeijer, C.: Continuous-flow isotope analysis of the deuterium/hydrogen ratio in atmospheric hydrogen, Rapid Comun. Mass. Sp., 18, 299306, 2004.

Sawa, Y., Machida, T., and Matsueda, H.: Seasonal variations of $\mathrm{CO}_{2}$ near the tropopause observed by commercial aircraft, J. Geophys. Res., 113, 23301, doi:10.1029/2008JD010568, 2008.

Schmidt, M., Graul, R., Sartorius, H., and Levin, I.: The Schauinsland $\mathrm{CO}_{2}$ record: 30 years of continental observations and their implications for the variability of the European $\mathrm{CO}_{2}$ budget, $\mathrm{J}$. Geophys. Res., 108, 4619, doi:10.1029/2002JD003085, 2003.

Shia, R.-L., Liang, M.-C., Miller, C. E., and Yung, Y. L.: $\mathrm{CO}_{2}$ in the upper troposphere: Influence of stratospheretroposphere exchange, Geophys. Res. Lett., 33, 14814, doi: 10.1029/2006GL026141, 2006.

Solomon, S., Qin, D., Manning, M., Chen, Z., Marquis, M., Averyt, K., Tignor, M., and Miller, H. (Eds.): Climate Change 2007: The Physical Science Basis. Contribution of Working Group I to the Fourth Assessment Report of the Intergovernmental Panel on Climate Change, Cambrigde University Press, 2007.

van Velthoven, P.: Meteorological analysis of CARIBIC by KNMI, 
http://www.knmi.nl/samenw/campaign_support/CARIBIC/\#LH, 2009.

Wexler, A.: Vapor pressure formulation for water in the range 0 to 100 C - A Revision, J. Res. NBS, 80A, 775-785, 1976.

Wuebbles, D. J. and Hayhoe, K.: Atmospheric methane and global change, Earth-Sci. Rev., 57, 177-210, doi:10.1016/ S0012-8252(01)00062-9, 2002.
Zahn, A., Brenninkmeijer, C. A. M., Maiss, M., Scharffe, D. H., Crutzen, P. J., Hermann, M., Heintzenberg, J., Wiedensohler, A., Güsten, H., Heinrich, G., Fischer, H., Cuijpers, J. W. M., and van Velthoven, P. F. J.: Identification of extratropical two-way troposphere-stratosphere mixing based on CARIBIC measurements of $\mathrm{O}_{3}, \mathrm{CO}$, and ultrafine particles, J. Geophys. Res., 105, 1527-1536, doi:10.1029/1999JD900759, 2000. 